International Journal of Automotive and Mechanical Engineering

ISSN: 2229-8649 (Print); ISSN: 2180-1606 (Online)

Volume 16, Issue 4 pp. 7211-7224 Dec 2019

(c) Universiti Malaysia Pahang, Malaysia

\title{
Aging Kinetics and Microstructural Features of Al6061-SiC+B 4 C Stir Cast Hybrid Composites
}

\author{
Sathyashankarasharma, Gurumurthy, Gowrishankar*, A. Kini, M. Shettar \\ and P. Hiremath
}

Department of Mechanical and Manufacturing Engineering, Manipal Institute of Technology, Manipal Academy of Higher Education, Manipal-576104, Karnataka, India

*Email: gowri.shankarmc@ manipal.edu

\begin{abstract}
The purpose of the current metallurgical work is to analyse the mechanical property alteration and microstructure evaluation of Al6061 hybrid composites by age hardening treatment using three different aging temperatures. Al6061 hybrid composites reinforced with $\mathrm{B}_{4} \mathrm{C}$ and $\mathrm{SiC}$ particles have been manufactured using two-stage stir casting method. The optical micrographs were analysed for the dispersivity of the reinforcements in the matrix. To assure the type of reinforcements in the matrix SEM analysis was carried out. It was found that during solutionising and aging at 100,150 and $200^{\circ} \mathrm{C}$, presence of $\mathrm{SiC}$ and $\mathrm{B}_{4} \mathrm{C}$ particles in the hybrid Al6061 matrix composites showed substantial improvement in hardness compared to that of the base alloy. Transmission electron microscopy (TEM) was used to identify the intermetallic phases, morphology and orientation of the particulates responsible for the peak aging behaviour. It was observed that while aging at $100^{\circ} \mathrm{C}$ excellent peak hardness values are observed in the composite group with well-distributed fine precipitates of $\mathrm{Mg}_{2} \mathrm{Si}$ along grain boundaries as well as within the grains. The composition Al6061-3B3S composites showed an additional secondary intermetallic phase viz., $\alpha-\mathrm{Al}_{12} \mathrm{Fe}_{3} \mathrm{SiMg}$ along with $\mathrm{Mg}_{2} \mathrm{Si}$, which is responsible for the superior aging behaviour over other compositions.
\end{abstract}

Keywords: A16061 hybrid composites; aluminium metal matrix composites (AMMCs); transmission electron microscopy; selective area diffraction pattern; intermetallics.

\section{INTRODUCTION}

The demand of Aluminium has escalated rapidly owing to its unique combination of properties enabling it as one of the most versatile engineering and construction materials [12]. Aluminium-magnesium-silicon alloys ( $\mathrm{Al}-\mathrm{Mg}-\mathrm{Si}$; also known as $6 \mathrm{xxx}$ series) are moderate strength, heat-treatable alloys with excellent formability and resistance to corrosion. The Al6061 alloy has been studied extensively due to its technological significance and a further increase in the strength is obtained by precipitation (age) hardening [3]. Aluminium metal matrix composites (AMMCs) reinforced with ceramic particles, viz., $\mathrm{SiC}, \mathrm{B}_{4} \mathrm{C}, \mathrm{Al}_{2} \mathrm{O}_{3}, \mathrm{TiC}$ have received considerable attention due to their high specific strength and modulus, low coefficient of thermal expansion and good resistance to wear [4]. These composites in recent years are mainly used in aerospace, automobile and marine applications. 
AMMCs reinforced with SiC particles enhance yield strength by up to $20 \%$, lower thermal expansion coefficient, higher elasticity modules and greater wear resistance compared to unreinforced matrix alloy systems [5-6]. The $\mathrm{B}_{4} \mathrm{C}$ reinforced $\mathrm{AMMCs}$ are harder, tougher, more fracture-resistant, lighter in weight and have higher fatigue strength and significantly improve properties compared to other materials. [7-9]. Whenever weight and strength are the most important parameters, $\mathrm{SiC}$ and $\mathrm{B}_{4} \mathrm{C}$ particulates reinforced $\mathrm{AMMCs}$ are a novel kind of innovative materials. The presence of $\mathrm{SiC}$ and $\mathrm{B}_{4} \mathrm{C}$ in hybrid metal matrix composites (HMMCs) results in improvement of wear resistance and strength to weight ratio than the unreinforced alloys [10-11]. HMMCs applications in the aerospace industry and components of automotive engines viz., driveshafts, cylinders, pistons and brake rotors have been found to create interest in studying the wear behaviour of structural components [11].

Precipitation hardening treatment improves the strength and hardness of alloy, by forming enormously tiny, homogenously dispersed particles of second phase within the original phase matrix [1]. Uvaraja et al. [11] investigated the effect of influence of SiC and $\mathrm{B}_{4} \mathrm{C}$ particulates reinforced composite on Al6061 matrix. It was observed that, HMMCs showed a high level of hardness as compared to alloy, because silicon carbide and boron carbide particles uniformly embedded in the Al6061 matrix. Aziz et al. [12] studied the heat treatment and wear properties of $\mathrm{Al}_{2} \mathrm{O}_{3}$ and $\mathrm{TiC}$ particulates in reinforced $\mathrm{Al} 6063$ hybrid composites. The hardness of the composites was improved after heat treatment due to the presence of reinforcements in composite, which accelerated the aging kinetics and caused an increase in dislocation density at the surrounding area of reinforcement particles. Benal et al. [13] studied the effects of reinforcement with $\mathrm{SiC}$ and E-glass fibres on wear properties of Al6061 hybrid composites. Due to the presence of both harder reinforcements and coherent precipitates in the matrix, increased hardness was observed during aging treatment.

Preparing Al6061-SiC- $\mathrm{Al}_{2} \mathrm{O}_{3}$ hybrid composites, Umanath et al. [14] studied the effect of stir casting processing method on the characterisation. It was observed that, by adding reinforcement particles to the alloy matrix, micro-hardness increases with increased reinforcement due to solid solution hardening of the matrix. Altinkok et al. [15] evaluated the tensile behaviour and microstructure of $\mathrm{Al}_{2} \mathrm{O}_{3} / \mathrm{SiC}_{\mathrm{p}}$ reinforced $\mathrm{AMMCs}$ fabricated by the stir casting technique. Strength of the hybrid composite was higher than the unreinforced alloy. The significant improvement in tensile strength of the composites was attributed to the grain and particle size, reinforcement shape and uniform distribution of particles in the alloy matrix. Uvaraja et al. [16] work focussed on the tribological behaviour of novel hybrid composite materials by varying $\mathrm{SiC}$ reinforcements and a fixed percentage of $\mathrm{B}_{4} \mathrm{C}$ particles. It was observed that the increase in hardness of composite is mainly due to the presence of harder $\mathrm{SiC}$ and $\mathrm{B}_{4} \mathrm{C}$ particles in the matrix alloy, which act as obstacles to the dislocation motion. Sharma et al. [17] work focussed on the metallography \& bulk hardness of artificially aged Al6061-B4C-SiC stir cast hybrid composites. It was found a significant improvement in hardness, tensile strength and a marginal decrease in ductility of hybrid composites as compared to aluminium alloy. Uthayakumar et al. [18] studied the wear performance of Al1 100-SiC-B ${ }_{4} \mathrm{C}$ hybrid composites under dry sliding condition. Increase in hardness and wear resistance was observed due to the presence of harder $\mathrm{SiC}$ and $\mathrm{B}_{4} \mathrm{C}$ reinforcement particles in the matrix alloy.

Uvaraja et al. [19] analysed the effect of reinforcements and artificial aging treatment on the wear resistance and hardness of stir cast A17071-SiC-B 4 C hybrid composites. Heattreated composites show higher hardness value as compared to Al6061 alloy. It was evident 
that the mechanical characterization and microstructural analysis would shed more light on the phenomena of precipitate formation, morphology, distribution and orientation vis-à-vis the reinforcement particles. Therefore, the objective of the current work was to characterise the peak aging behaviour of HMMCs of Al6061 reinforced with $\mathrm{SiC}$ and $\mathrm{B}_{4} \mathrm{C}$ particulates through detailed microstructural analysis.

\section{MATERIALS AND METHODS}

\section{Synthesis of Hybrid Composites}

The $\mathrm{B}_{4} \mathrm{C}$ powder (particles size $\sim 35-40 \mu \mathrm{m}$ ) was supplied by M/s Boron Carbide India Ltd. Mumbai and $\mathrm{SiC}$ powder (particles size $~ 35-40 \mu \mathrm{m}$ ) was supplied by M/s Indian Fine Chemicals Ltd., Mumbai. Al6061(wt. \%: 0.52Si, 0.95Mg, 0.55Fe, 0.24Cu, 0.14Mn, 0.25Cr and remainder Al) billets were delivered by M / S Perfect Metal Works Ltd., Bangalore, India and are melted in a graphite crucible by $5 \mathrm{~kW}$ electrical resistance furnace and the process of melting was continued until an identical temperature of $750^{\circ} \mathrm{C}$ was reached.

A small quantity of "scum powder" was tipped in the melt, to take out the slag or flux. By the addition of dry hexachloroethane $\left(\mathrm{C}_{2} \mathrm{Cl}_{6}, 0.3 \%\right.$ wt.\%) tablet [20], the entire melt was then degassed. To take out the volatile substances, surface impurities and enhance the wettability of the reinforcements, $\mathrm{B}_{4} \mathrm{C}$ particles were preheated to $250^{\circ} \mathrm{C}$ for 2 hours. Preheating $\mathrm{B}_{4} \mathrm{C}$ above $300^{\circ} \mathrm{C}$ would lead to agglomeration of reinforcement particles due to formation of $\mathrm{B}_{2} \mathrm{O}_{3}$ layer [7]. To take out the volatile matters, the $\mathrm{SiC}$ particles were preheated to $800^{\circ} \mathrm{C}$ for 2 hours. Preheating steers to artificial oxidation by modifying the composition of the surface, resulting in the formation of $\mathrm{SiO}_{2}$ layer on $\mathrm{SiC}$ particles surface. This layer of $\mathrm{SiO}_{2}$ reacts with molten aluminium to form a thin continuous layer of reaction consisting primarily of an $\mathrm{Al}-\mathrm{Si}-\mathrm{O}$ compound. This chemical reaction is thermodynamically favoured, has a negative value of its Gibbs free energy and increases the adhesion work resulting in an improvement of the particle wettability [21-23].

Table 1. Composition designation and details of stir cast Al6061 HMMCs.

\begin{tabular}{lc}
\hline Composition designation & Composition details \\
\hline 1B5S & 1 wt.\% Boron carbide, 5 wt.\% Silicon carbide, rest A16061 \\
2B4S & $2 \mathrm{wt} \%$ Boron carbide, 4 wt.\% Silicon carbide, rest A16061 \\
3B3S & $3 \mathrm{wt} \%$ Boron carbide, 3 wt.\% Silicon carbide, rest A16061 \\
\hline
\end{tabular}

The melt was let to cool down to a semisolid state at $600^{\circ} \mathrm{C}$ (slightly below the liquid temperature). Preheated boron carbide (1,2 and $3 \mathrm{wt}$. \%) and silicon carbide powder (5, 4 and 3 wt. \%) were poured into the vortex formed during stirring at this stage in varying proportions. The composition details are shown in Table 1. The combined weight fraction of the reinforcements was limited to $6 \mathrm{wt}$. \% in order to prevent agglomeration and improper distribution during stirring. The stirring speed was maintained at 150-200 rpm for 10 minutes. The composite mixture was reheated up to a temperature of $750 \pm 10^{\circ} \mathrm{C}$, after mixing the reinforcement in semi-solid state and again stirring continued at an average stirring speed of $400 \mathrm{rpm}$ for 10 minutes. Then the melt was poured into the moulds of preheated $\left(500^{\circ} \mathrm{C}\right)$ cast iron. 
For analysing the dispersion of $\mathrm{SiC}$ and $\mathrm{B}_{4} \mathrm{C}$ particles, tetragonal specimens of $10 \mathrm{~mm}$ $\times 10 \mathrm{~mm} \times 15 \mathrm{~mm}$ were cut from different regions of the cast components. The specimens were finely polished, buffed and etched with Keller's reagent to highlight the reinforcement phases. The cast samples are analysed by "inverted metallurgical optical microscope (IM 7000) to ensure the uniform dispersion of boron and silicon carbide particles. In addition to this, Al6061-3B3S specimen were analysed using JEOL JSM 840A scanning electron microscope equipped with energy-dispersive $\mathrm{x}$-ray spectroscopy (EDXS) to assess the distribution and composition of the reinforcement particles within the Al6061 matrix.

\section{Artificial Aging Treatment and Hardness Testing}

Hardness tests were carried out for both as-cast and age hardened HMMC's in adherence to ASTM E10-00 standard using Brinell hardness scale employing a ball indenter of diameter $5 \mathrm{~mm}$ with a load of $250 \mathrm{kgf}$. The treatment for age hardening consisted of solutionizing at $558^{\circ} \mathrm{C}$ for $2 \mathrm{~h}$ duration followed by quenching at room temperature in demineralized water. The quenched samples were aged in the furnace at 100,150 and $200^{\circ} \mathrm{C}$ for a time interval of 1 hour during which the peak aging and over aging took place. The melting of the ternary eutectic phase $\mathrm{Mg}_{2} \mathrm{Si}-(\mathrm{Al})-(\mathrm{Si})$ occurs at $558^{\circ} \mathrm{C}$, according to the $\mathrm{Al}-\mathrm{Mg}$-Si phase diagram. As a reinforcement phase, $\mathrm{Mg}_{2} \mathrm{Si}$ was found to completely dissolve at $558^{\circ} \mathrm{C}$ during solutionising and precipitate during aging to amplify the reinforcing effect [24].

\section{Preparation of Sample for TEM}

Thin foils were obtained from peak aged samples using slow-speed diamond saw and mechanically thinned down to a thickness of $\sim 0.1 \mathrm{~mm}$ for transmission electron microscopy (TEM). Then, $0.1 \mathrm{~mm}$ thin foils underwent blanking operation of punching to obtain discs of $3 \mathrm{~mm}$ diameter. Then these discs were treated with an electropolishing method. The metal in the middle of the sample is oxidized during electropolishing and dissolved in an electrolyte. Finally, the sample would get a hole, and it would be very thin in the area around the hole. The electropolishing was done using a Struers Tenupol-5 with a mixture of acetic $\mathrm{CH}_{3} \mathrm{COOH}$ and perchloric acids $\mathrm{HClO}_{4}$ (voltage $\sim 25 \mathrm{~V}$ and temperature $\sim 6^{\circ} \mathrm{C}$ ). The other electrolyte that was used was $1 / 3$ nitric acid $\mathrm{HNO}_{3}$ and $2 / 3$ methanol $\mathrm{CH}_{3} \mathrm{OH}$. The sample was cooled down to -20 to $-30^{\circ} \mathrm{C}$ using liquid nitrogen. Then, the perforated $3 \mathrm{~mm}$ disc samples were studied in an analytical transmission electron microscope (Philips CM 200, Scripps Research Institute, La Jolla, CA, United States) operated at $200 \mathrm{kV}$ using imaging, Selected Area Diffraction Pattern (SADP) method and EDXS.

\section{RESULTS AND DISCUSSION}

\section{Distribution of Reinforced Particles in HMMCs}

In order to obtain superior mechanical properties in the composites, consistent dispersion of the reinforcement is essential. The optical microscopy describes the Al6061alloy and composites (1B5S, 2B4S and 3B3S) microstructures. Figure 1(a) to 1(d) displays optical micrographs and endorses the uniform alloy matrix distribution of $\mathrm{SiC}$ and $\mathrm{B}_{4} \mathrm{C}$ particles. There was no agglomeration of reinforcements observed in the matrix. The casting defects 
like blow holes or air pockets were absent. Figure 2 shows the SEM micrographs of polished Al6061-3B3S HMMCs and the corresponding EDXS at different particle locations confirm the presence of $\mathrm{SiC}$ and $\mathrm{B}_{4} \mathrm{C}$ particles respectively. SEM micrographs confirm the consistent distribution of $\mathrm{SiC}$ and $\mathrm{B}_{4} \mathrm{C}$ particle in A16061 alloy matrix.

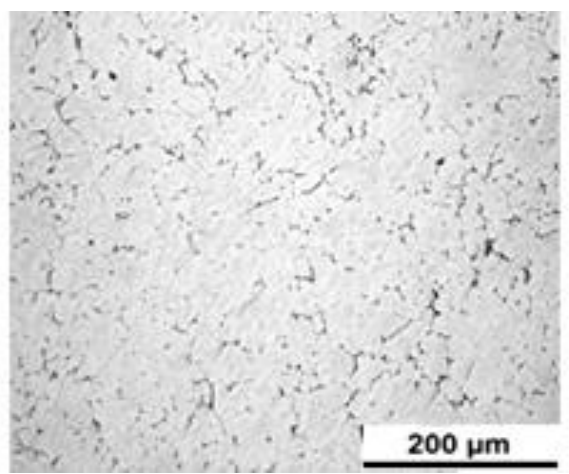

(a)

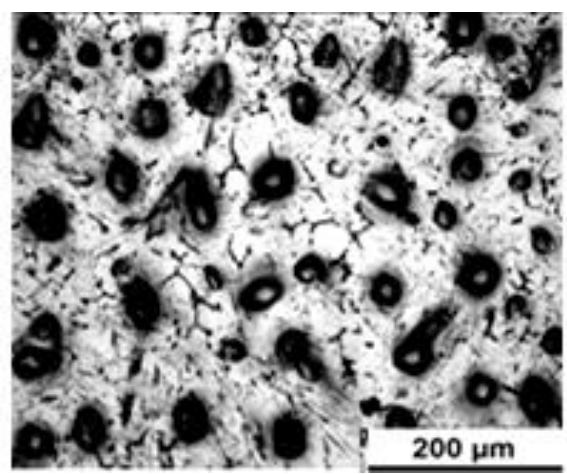

(c)

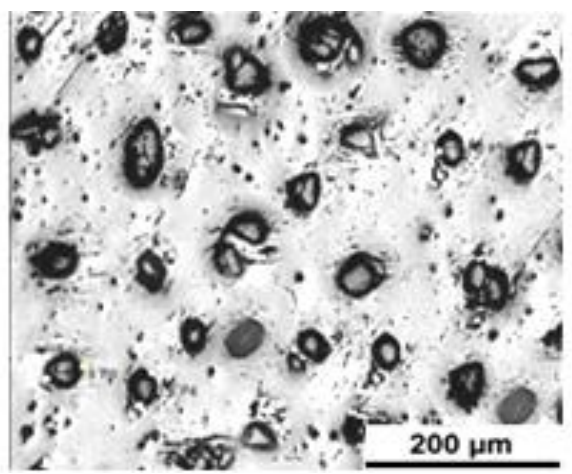

(b)

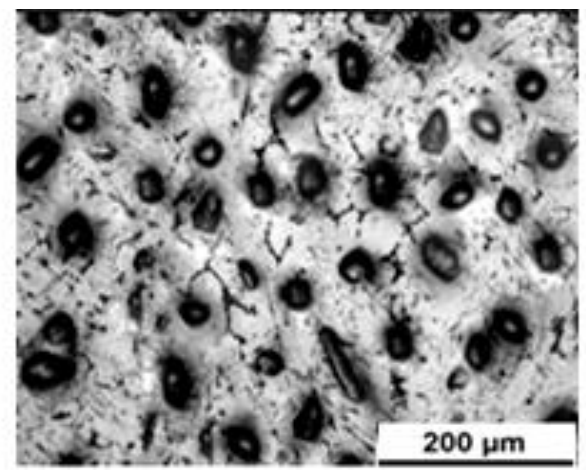

(d)

Figure 1. Optical photograph of (a) Al6061 alloy, (b) Al6061-1B5S, (c) Al6061-2B4S and (d) Al6061-3B3S hybrid composites.

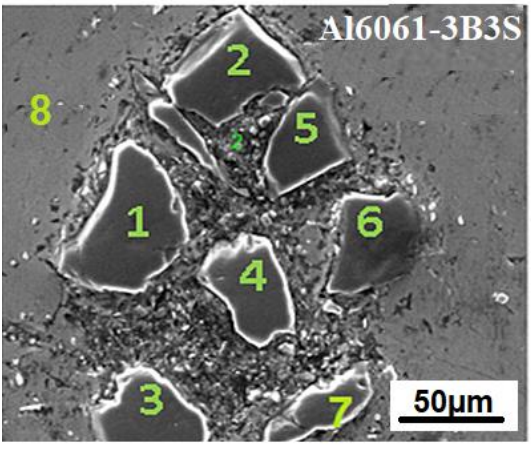

(a)

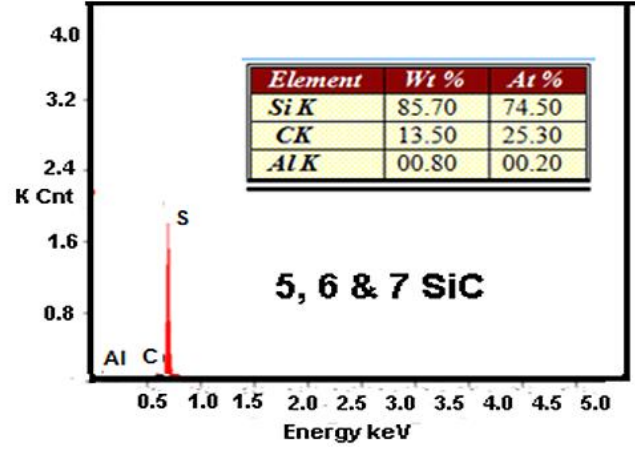

(b) 


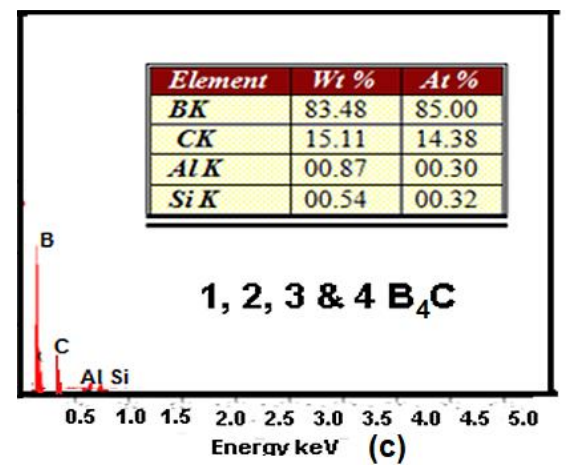

(c)

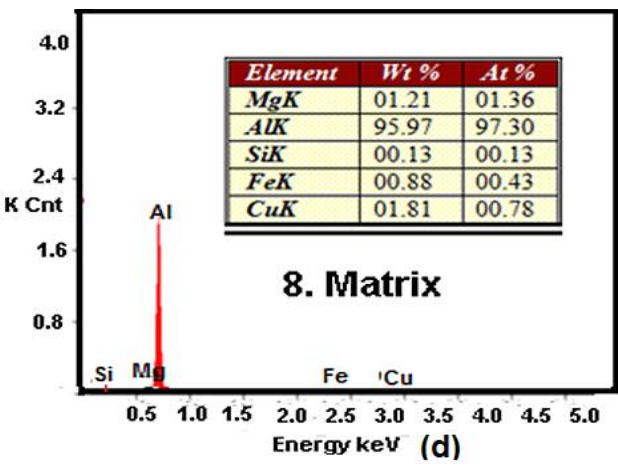

(d)

Figure 2. (a) SEM image of as-cast A16061-3B3S hybrid composite microstructure, EDXS of (b) $\mathrm{SiC}$, (c) $\mathrm{B}_{4} \mathrm{C}$ and (d) matrix Al6061 alloy, measured at marked spots of 1-8.

\section{Aging Curve and Hardness}

The aging kinetics of the base Al6061 alloy and the HMMCs is shown in Figure 3. The hardness was found to increase gradually with time for both, the base alloy and the HMMCs. But the duration to achieve peak aging was found to be reduced with the increase in weight fraction of $\mathrm{B}_{4} \mathrm{C}$ at all the aging temperatures. The aging behaviour in alloys of $\mathrm{Al}-\mathrm{Mg}-\mathrm{Si}$ involves the diffusion-controlled mechanism of aluminium matrix atoms of $\mathrm{Mg}$ and $\mathrm{Si}$. Thus, any modification in the matrix leads to a change in the diffusivities of the alloying elements forming a precipitate and also changes the matrix's aging response. After solutionising treatment, the presence of chemically stable and low thermal expansion coefficient (CTE) reinforcement particles induced stress in the matrix resulting in substantial plastic flow, to enhance dislocation density near the interface [25]. The resulting higher dislocation density provided heterogeneous nucleation sites for precipitation and high diffusivity for alloy element diffusion $[12,26]$.

In cast samples, the room temperature structure contains dual phase with saturated solid solution and intermetallics. These intermetallics are a harder phase and hardness is higher at room temperature. After solutionising, aging starts from zero time and the resultant room temperature structure is supersaturated solid solution without any secondary intermetallics. This supersaturated solid solution is the soft phase structure with lower hardness, as shown in Figure 4 at zero time. As the aging continuous, the secondary intermetallic phases spontaneously separate out from the parent supersaturated phase and hardness increases [27-28]. It was apparent that the existence of hardest reinforcements in the matrix accelerated the aging kinetics, obtained by the difference in $\mathrm{CTE}$ of the reinforcements and matrix. The $\mathrm{CTE}$ of $\mathrm{SiC}\left(5 \times 10^{-6} /{ }^{\circ} \mathrm{C}\right)$ and $\mathrm{B}_{4} \mathrm{C}\left(4 \times 10^{-6} /{ }^{\circ} \mathrm{C}\right)$ is less than that of aluminium alloy $\left(23 \times 10^{-6} /{ }^{\circ} \mathrm{C}\right)$. The augmented aging built-up back stress and work hardening effect close to the interface of the $\mathrm{Al} 6061$ matrix and $\mathrm{SiC}-\mathrm{B}_{4} \mathrm{C}$ reinforcements.

Among all the aging temperatures, aging at $100^{\circ} \mathrm{C}$ in both, the base alloy and the HMMC, showed the highest peak hardness values although the time intervals for achieving the peak aging were considerably higher. Lower temperature aging (at $100^{\circ} \mathrm{C}$ ) contributed to the increased hardness due to an escalation in the number of intermediate regions during precipitation, increased number of finer intermetallics and reduced interparticle distances. 
Due to the coarsening of intermetallic precipitates that form during aging and the existence of incoherency between matrix and intermetallics characterized as over - aging, the hardness value decreased after peak aging condition. Over-aging induced alloy softness that caused a drastic decrease in the hardness value. Because of the increased diffusion rate in the matrix due to higher temperatures accelerated the aging kinetics. The aging temperature is higher, the time needed to achieve peak hardness is lower [24].

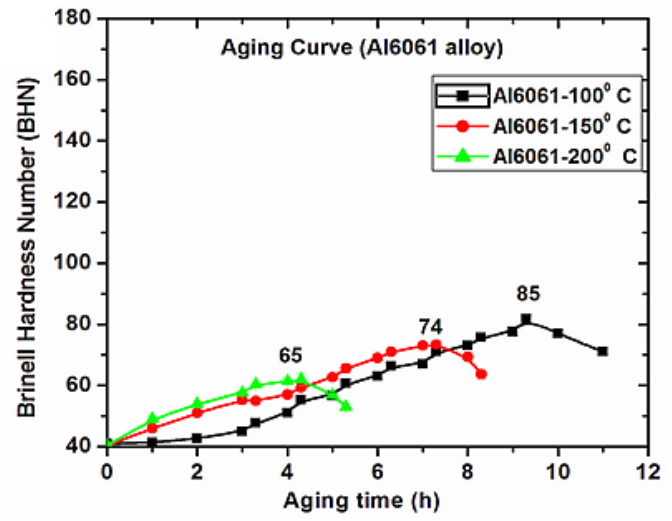

(a)

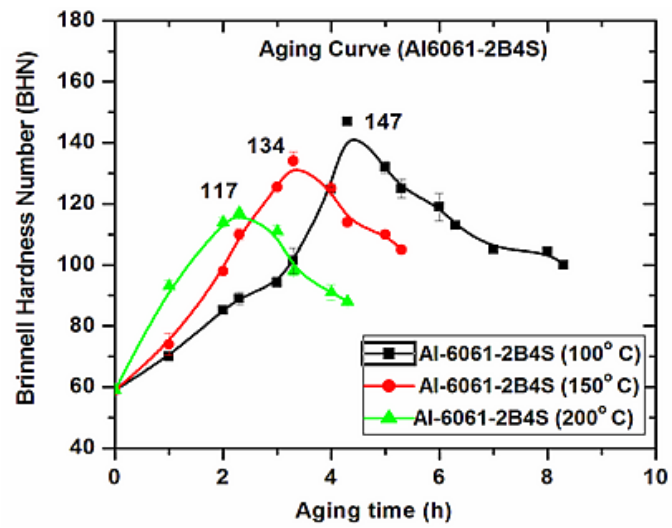

(c)

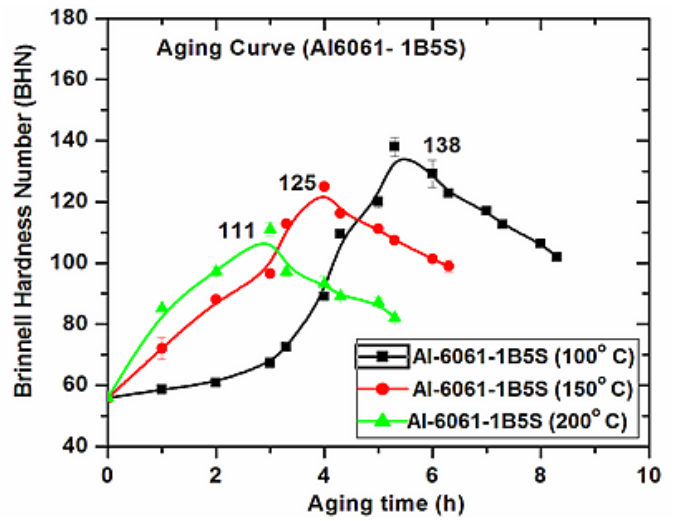

(b)

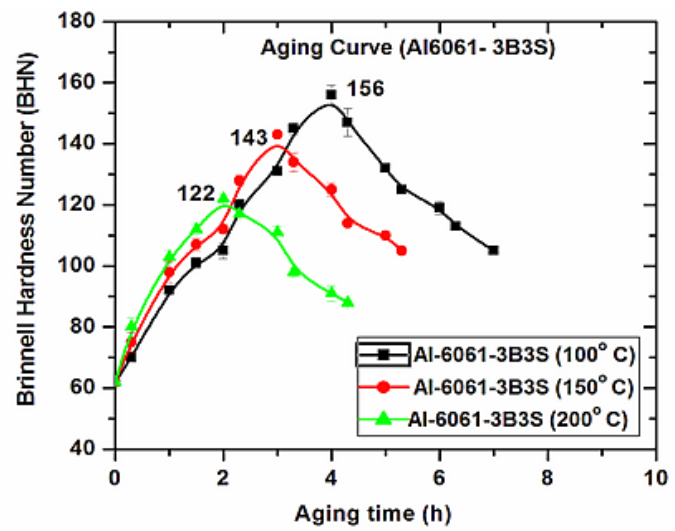

(d)

Figure 3. Aging curves of (a) Al6061 alloy, (b) Al6061-1B5S, (c) Al6061-2B4S and (d) Al6061-3B3S hybrid composites aged at 100, 150 and $200^{\circ} \mathrm{C}$.

With an increase in $\mathrm{B}_{4} \mathrm{C}(1,2 \& 3$ wt. \%) and reduction in $\mathrm{SiC}(5,4 \& 3$ wt.\%), the hardness was found to increase in both as-cast and age hardened specimens. The as-cast $3 \mathrm{~B} 3 \mathrm{~S}$ HMMC showed an increase in $\mathrm{BHN}$ value $~ 74 \%$ (87 $\mathrm{BHN}$ ) compared to the as-cast base alloy (50 BHN). 3B3S HMMC showed additional improvement in hardness as compared to 1B5S and 2B4S HMMCs. There is a large difference in the density and hardness of SiC and $\mathrm{B}_{4} \mathrm{C}$ particles, where hardness of $\mathrm{B}_{4} \mathrm{C}$ is higher. A small increment of the lower density of $\mathrm{B}_{4} \mathrm{C}$ in the matrix constitutes large quantity compared to $\mathrm{SiC}$ particles of same wt \%., which leads to an increase in hardness. The dislocation density in hybrid composites depends on the size of the used reinforcements [12]. Though in the current work, the sizes of both particles, $\mathrm{SiC}$ and $\mathrm{B}_{4} \mathrm{C}$, were the same $(35 \sim 40 \mu \mathrm{m})$, the density difference between $\mathrm{B}_{4} \mathrm{C}\left(2.52 \mathrm{~g} / \mathrm{cm}^{3}\right)$ 
and $\mathrm{SiC}\left(3.1 \mathrm{~g} / \mathrm{cm}^{3}\right)$ led to higher volume fraction of $\mathrm{B}_{4} \mathrm{C}$ particles causing smaller interparticle distance in the matrix and accordingly higher dislocation density than $\mathrm{SiC}$ particles [12]. The precipitation of secondary solute rich phases during age hardening in 3B3S was confirmed through SEM studies taken up for specimens aged at $100^{\circ} \mathrm{C}$ which emerged as the most suitable temperature for optimal peak aging behaviour.

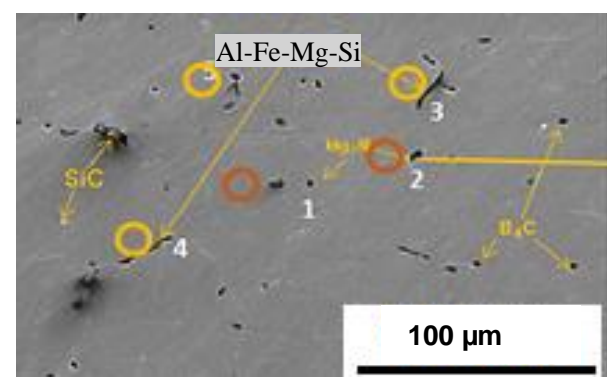

(a)

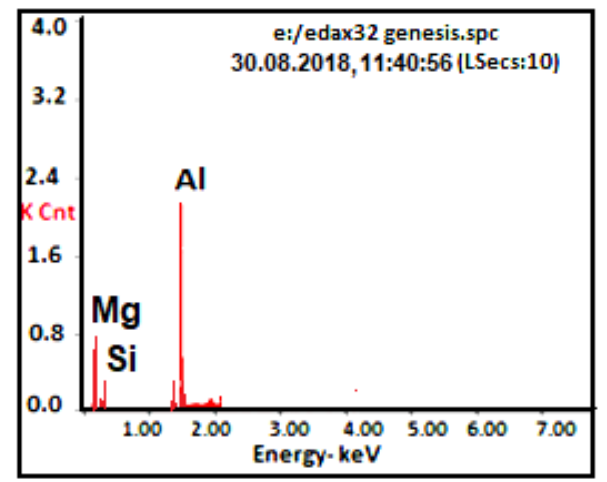

(c)

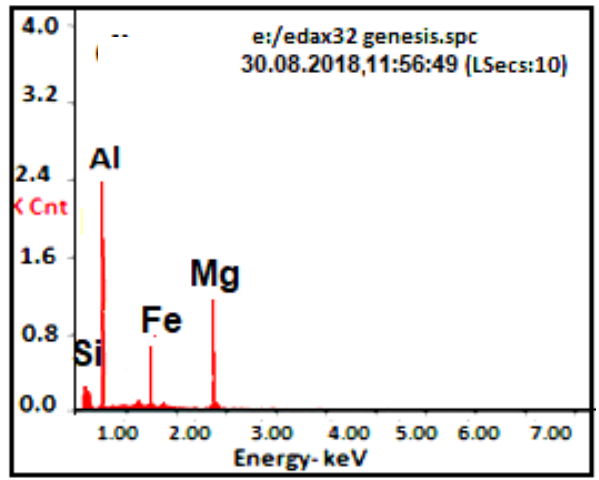

(d)

Figure 4. (a) and (b) SEM images of Al6061-3B3S hybrid composite peak aged at $100^{\circ} \mathrm{C}$

(c) and (d) EDXS showing Al-Fe-Si-Mg and $\mathrm{Mg}_{2} \mathrm{Si}$ precipitates composition.

The SEM with EDXS analysis of $100^{\circ} \mathrm{C}$ aged Al6061-3B3S composite at higher magnification, besides $\mathrm{SiC}$ and $\mathrm{B}_{4} \mathrm{C}$ particles, showed the presence of $\mathrm{Mg}_{2} \mathrm{Si}$ and $\mathrm{Al}-\mathrm{Fe}-\mathrm{Si}$ $\mathrm{Mg}$ precipitated phases in the aluminium matrix (Figure 4). Al-Fe-Mg-Si was located mostly along the grain boundaries whereas $\mathrm{Mg}_{2} \mathrm{Si}$ was localized within the matrix while Al60611B5S and Al6061-2B4S did not show the presence of secondary Al-Fe-Si-Mg phase. The combined effect of the reinforcements as well as the dual forms of precipitated phases occurred during aging enhanced the hardness of Al6061-3B3S as compared to Al6061-1B5S and A16061-2B4S.

\section{Precipitate Phase Analysis by Means of TEM}

Microstructural investigation and phase identification for the peak aged samples (Al6061 alloy and Al6061-3B3S hybrid composites) were performed using TEM and SADP method. The presence of $\beta$ " \& $\beta$ ' in aluminium matrix results in satellite spots and streaks in SADP [27-29]. The $\beta$ " are fine needle-shaped zones along $\langle 100\rangle \mathrm{Al}$, with a monoclinic structure, 
and the $\beta$ ' phases are usually platelets on $\{100\}$ of $\mathrm{Al}$ having the face-centred cubic (FCC) structure. During the artificial aging of aluminium alloy, hardening is mainly caused by the precipitation of needle-like $\beta$ " phase. The presence of a bulk number of minute spots in the bright-field (BF) TEM images denotes the $\beta$ " needles along [001 $]_{\mathrm{Al}}$ plane of the Al matrix [30].

Figure 5 shows BF TEM images of Al6061 alloy samples peak aged at $100^{\circ} \mathrm{C}$ and EDXS performed at the marked position under different magnifications at nano level. Figure 5(a) to 5(c) show second phase precipitates of needle/rod and rectangular shape precipitated during aging. It was found that these phases are metastable semicoherent $\mathrm{Mg}_{2} \mathrm{Si}\left(\beta^{\prime \prime}\right)$ and the amount of these precipitated phases show the presence of $\mathrm{Mg}$ and $\mathrm{Si}$, which is confirmed through EDXS displayed in Figure 5d. The existence of an excessive percentage of Al was due to matrix effect with a detection limit of $99 \%$ of confidence. In age-hardening theory, during aging the peak hardness is obtained due to the formation of metastable semi-coherent $\mathrm{Mg}_{2} \mathrm{Si}\left(\beta^{\prime \prime}\right)$ phase. In the present work the peak hardness obtained by the experiment is explained in Figure 6.

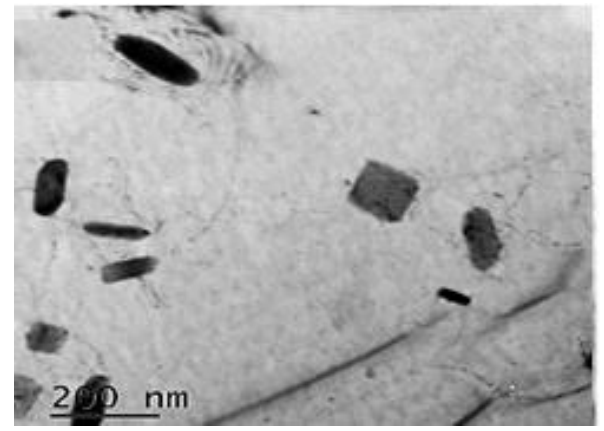

(a)

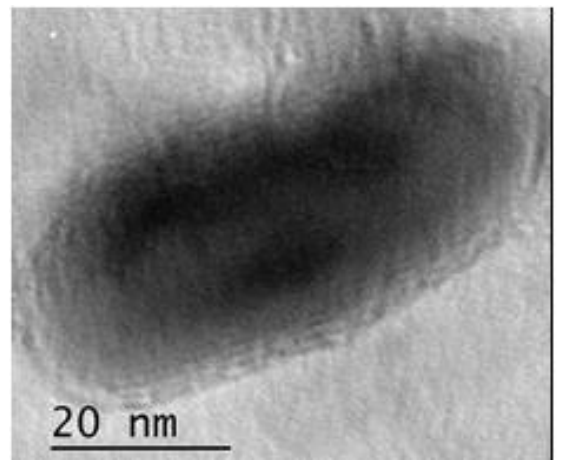

(c)

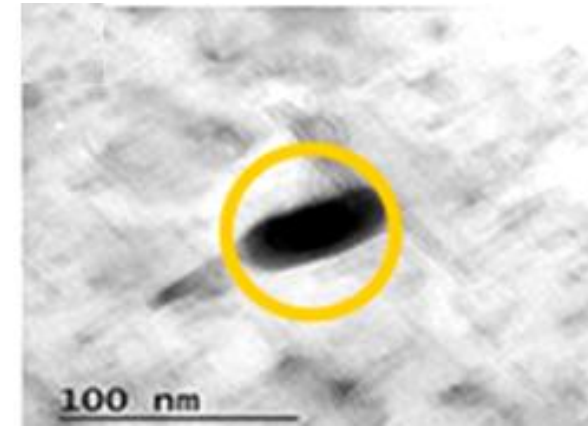

(b)

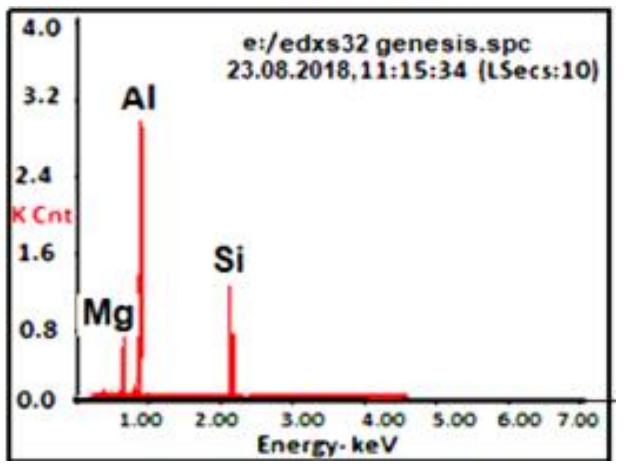

(d)

Figure 5. (a), (b), (c) BF TEM images of Al6061 alloy peak aged at $100^{\circ} \mathrm{C}$ with (d) EDXS spectrum of $\mathrm{Mg}_{2} \mathrm{Si}$ precipitate.

BF TEM image, experimental and schematic SADP of Al6061 alloy peak aged at $100^{\circ} \mathrm{C}$ are shown in Figures 6(a) to 6(c), where both, streaks and satellite spots, indicate the presence of $\mathrm{Mg}_{2} \mathrm{Si}$ particles in the T6-treated-A16061 alloy [30]. Larger diffraction spots are associated with Al matrix with [012] zone axis, while tinier spots can be attributed to the 
precipitated phase. (" $\mathrm{Mg}_{2} \mathrm{Si}$ - card number: International Center for Diffraction Data-Powder Diffraction File (ICDD-PDF): 35-773") endorsed through SADP. Its zone axis is [001] which has been shown in Figures 6(b) and 6(c).

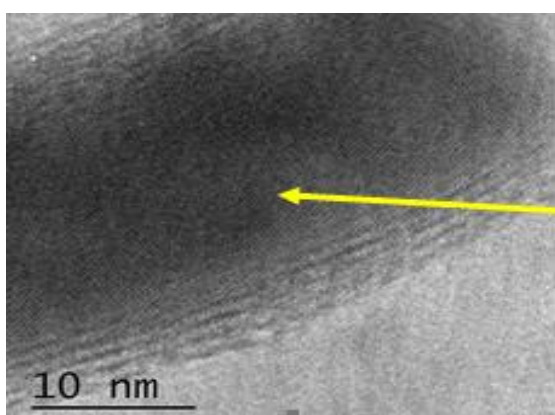

(a)

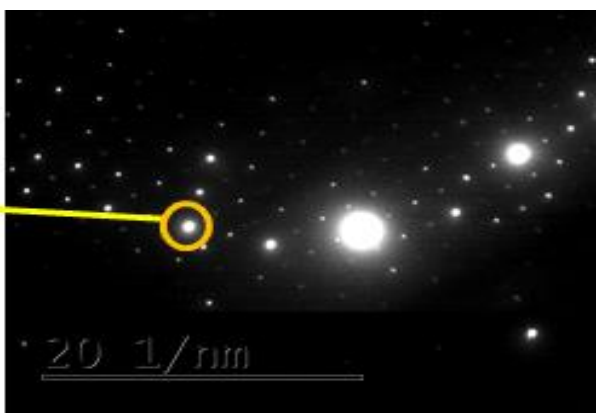

(b)

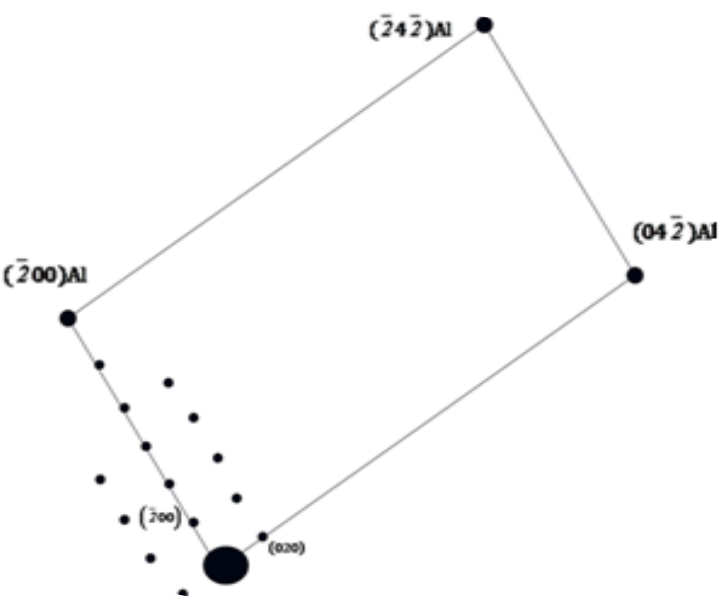

(c)

Figure 6. (a) BF TEM image of $\mathrm{Al} 6061$ alloy peak aged at $100^{\circ} \mathrm{C}$ showing precipitate of intermetallic phase with (b) experimental and (c) schematic SADP of this phase.

Figure 7 shows the BF TEM images of the investigated Al6061-3B3S in peak aged condition at $100^{\circ} \mathrm{C}$. Figure 7 (a) illustrates the presence of intermetallic phases. It was seen that these phases were highly tangled with dislocations resulting in the improvement of hardness. The movements of dislocations were restricted by the intermetallic particles at site "A" and "B" shown in Figure 7(b). Figure 7(c) shows the SADP of particle at site "A" with a corresponding zone axis [001] (EDXS card number -ICDD-PDF:35-773). Figure 7(e) shows the EDXS investigation for the same particle (Figure 7d) which confirms presence of $\mathrm{Mg}_{2} \mathrm{Si}$ phase. Figure 8(a) shows SADP of the precipitated particle at site "B". The phase was found to be $\alpha-\mathrm{Al}_{12} \mathrm{Fe}_{3} \mathrm{SiMg}$ indexed according to EDXS card number ICDD-PDF 71-4015 and its corresponding zone axis was $[\overline{1} \overline{3} 7]$. EDXS result shown in Figures 8(b) and 8(c) also confirmed the presence of Al-Mg-Si-Fe phase. The precipitate density appears to be higher in the composite than in the base alloy and peak aging occurs when most solute - rich precipitates disperse evenly throughout the matrix in a fine scale [31]. 


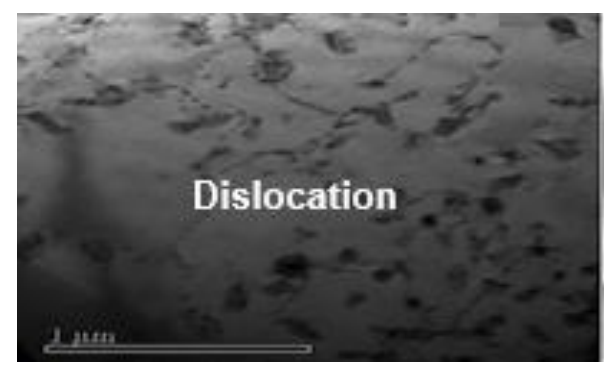

(a)

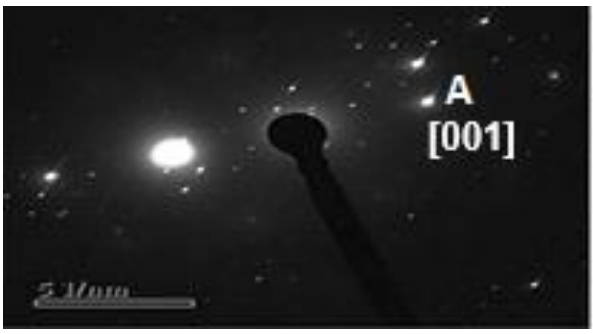

(c)

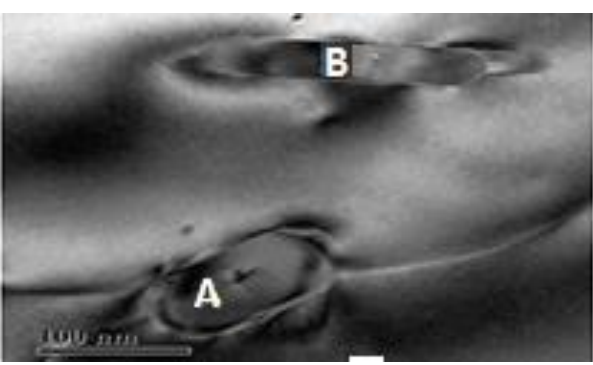

(b)

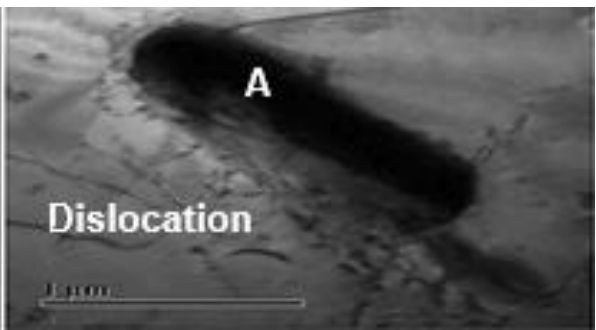

(d)

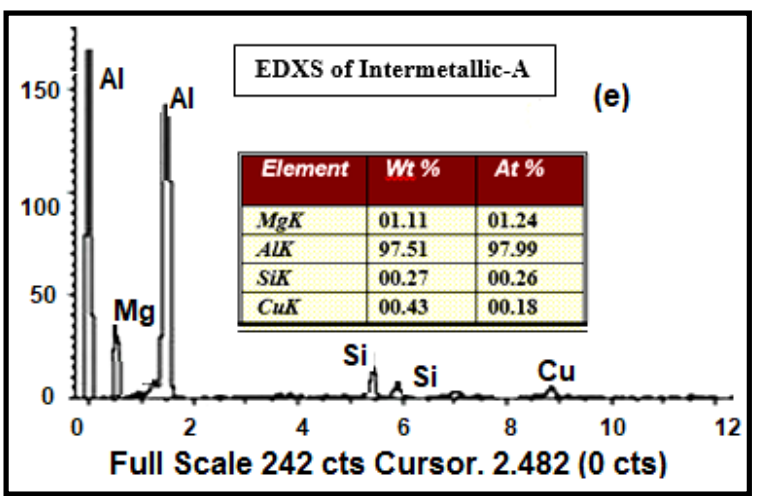

Figure 7. BF TEM micrographs of Al6061-3B3S composition showing (a) dislocation boundaries, (b) precipitated particles after peak aging at $100{ }^{\circ} \mathrm{C}$ (c) SADP of particle "A" with (d) a higher magnification micrograph and (e) EDXS of particle "A"

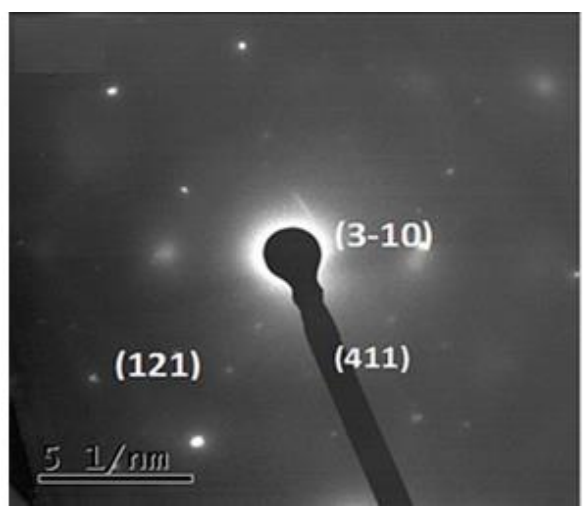

(a)

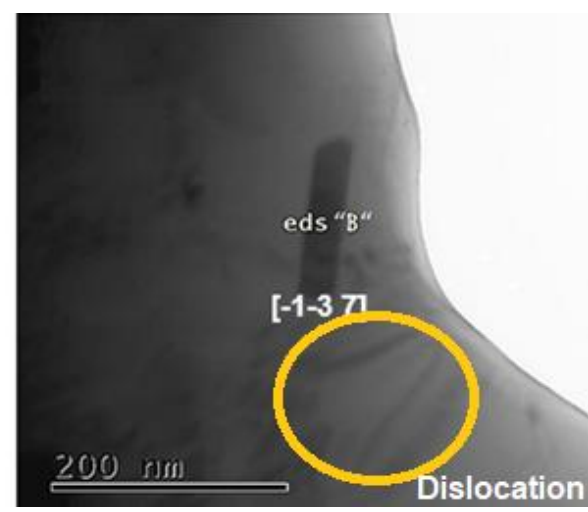

(b) 


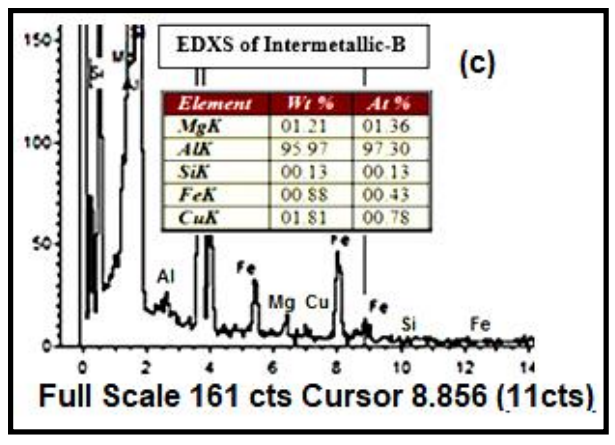

Figure 8. (a) SADP, (b) BF TEM image, and (c) EDXS of precipitated particle "B" of Al6061-3B3S composition.

\section{CONCLUSION}

Al6061-B 4 C-SiC hybrid composites were successfully produced by two-step stir casting process. The presence of $\mathrm{B}_{4} \mathrm{C}$ and $\mathrm{SiC}$ particles and their uniform dispersion within the Al6061 matrix was confirmed through optical microscopy and SEM. As-cast and artificially aged HMMCs showed higher hardness than the corresponding base Al6061 alloy. Among all the compositions, A16061-3B3S showed the best aging behaviour. Optimal peak aging for all compositions was observed to be $100^{\circ} \mathrm{C}$. The characterisation of the aging behaviour of Al6061-3B3S HMMC through TEM yielded the following conclusion:

i. The dislocation boundary and precipitation of secondary intermetallic phases along grain boundary were clearly identified.

ii. SADP analysis for Al6061-3B3S composition confirmed the presence and orientation of the intermetallic phases: $\mathrm{Mg}_{2} \mathrm{Si}$ and $\alpha-\mathrm{Al}_{12} \mathrm{Fe}_{3} \mathrm{SiMg}$.

iii. The presence of highly tangled phases with dislocations and the restriction offered by the intermetallic particles to the movement of dislocations was evident.

\section{REFERENCES}

[1] Hussain F, Abdullah S, Nuawi MZ. Effect of temperature on fatigue life behaviour of aluminium alloy AA6061 using analytical approach. Journal of Mechanical Engineering and Sciences. 2016;10(3):2324-2335.

[2] Sharma S, Kini A, Shankar G, Rakesh TC, Raja H, Chaitanya K, Shettar M. Tensile fractography of artificially aged Al6061-B 4 C composites. Journal of Mechanical Engineering and Sciences. 2018;12(3):3866-3875.

[3] Shankar MC, Sharma SS, Shetty R, Vinay K. Quality enhancement of TIG welded Al6061 $\mathrm{SiC}_{\mathrm{p}}$ composites by age hardening Process. International Journal of Automotive and Mechanical Engineering. 2018;15(3):5573-5582.

[4] Rao VR, Ramanaiah N, Rao MS, Sarcar MM, Kartheek G. Optimisation of process parameters for minimum volumetric wear rate on AA7075-tic metal matrix composite. International Journal of Automotive and Mechanical Engineering. 2016;13(3): 3669-3680.

[5] Rajesh R, Sharma S, Gowrishankar MC. Influence of solutionising and aging treatments on mechanical behaviour of stir-cast eutectoid steel powder reinforced 
Al7075 metal matrix composites. International Journal of Automotive and Mechanical Engineering. 2018;15(3):5583-5591.

[6] Lakshmanan P. Abrasive wear behaviour of aluminium hybrid nanocomposites produced by ultrasonication assisted casting method. International Journal of Automotive and Mechanical Engineering. 2017;14(3):4561-4573.

[7] Mahesh VP, Nair PS, Rajan TP, Pai BC, Hubli RC. Processing of surface-treated boron carbide-reinforced Aluminium matrix composites by liquid-metal stir-casting technique. Journal of Composite Materials. 2011;45(23):2371-2378.

[8] Onoro J, Salvador MD, Cambronero LE. High-temperature mechanical properties of aluminium alloys reinforced with boron carbide particles. Materials Science and Engineering: A. 2009;499(1):421-426.

[9] Shorowordi KM, Laoui T, Haseeb AS, Celis JP, Froyen L. Microstructure and interface characteristics of $\mathrm{B}_{4} \mathrm{C}$, sic and $\mathrm{Al}_{2} \mathrm{O}_{3}$ reinforced $\mathrm{Al}$ matrix composites: a comparative study. Journal of Materials Processing Technology. 2003;142(3):73843.

[10] Swamy NP, Ramesh CS, Chandrashekar T. Effect of heat treatment on strength and abrasive wear behaviour of Al6061-SiC $\mathrm{p}$ composites. Bulletin of Materials Science. 2010; 33(1):49-54.

[11] Uvaraja VC, Natarajan N. Tribological characterization of stir-cast hybrid composite Aluminium 6061 reinforced with sic and $\mathrm{B}_{4} \mathrm{C}$ particulates. European Journal of Scientific Research. 2012;76(4):539-552.

[12] Aziz MA, Mahmoud TS, Zaki ZI, Gaafer AM. Heat treatment and wear characteristics of $\mathrm{Al}_{2} \mathrm{O}_{3}$ and tic particulate reinforced AA6063 alloy hybrid composites. Journal of Tribology. 2006;128(4):891-904.

[13] Benal MM, Shivanand HK. Effects of reinforcement content and ageing durations on wear characteristics of Al6061 based hybrid composites. Wear. 2007;262(5-6):759763.

[14] Umanath K, Selvamani ST, Palanikumar K. Friction and wear behaviour of Al6061 alloy $\left(\mathrm{SiC}_{\mathrm{p}}+\mathrm{Al}_{2} \mathrm{O}_{3}\right)$ hybrid composites. International Journal of Engineering Science and Technology. 2011;3(7):5441-5451.

[15] Altinkok N, Coban A. The tensile behaviour and microstructure of $\mathrm{Al}_{2} \mathrm{O}_{3} / \mathrm{sic}_{\mathrm{p}}$ reinforced aluminium-based mmcs produced by the stir casting method. International Journal of Science and Advanced Technology. 2012;2:78-86.

[16] Uvaraja VC, Natarajan N, Rajendran I, Sivakumar K. Tribological behaviour of novel hybrid composite materials using Taguchi technique. Journal of Tribology. 2013;135(2):2110-2110.

[17] Sharma SS, Jagannath K, Prabhu PR, Gowri S, Harisha SR, Kini UA. Metallography \& bulk hardness of artificially aged A16061-B 4 C-sic stir cast hybrid composites. Material Science Forum 2017: 880:140-143.

[18] Uthayakumar M, Aravindan S, Rajkumar K. Wear performance of Al-sic-B ${ }_{4} \mathrm{C}$ hybrid composites under dry sliding conditions. Materials \& Design. 2013;47:456-464.

[19] Uvaraja VC, Natarajan N, Sivakumar K, Jegadheeshwaran S, Sudhakar S. Tribological behaviour of heat treated $\mathrm{Al} 7075$ aluminium metal matrix composites. Indian Journal of Engineering and Materials Sciences. 2015;22 :51-61.

[20] Gruzleski JE, Closest BM. The treatment of liquid aluminium and silicon alloys. American Foundrymen's Society Inc. 1990;1: 170-172 
[21] Pech-Canul MI. Aluminium alloys for $\mathrm{Al} / \mathrm{SiC}$ composites. Recent trends in processing and degradation of aluminium alloys. 2011:299-314.

[22] Urena A, Martınez EE, Rodrigo P, Gil L. Oxidation treatments for sic particles used as reinforcement in aluminium matrix composites. Composites Science and Technology. 2004;64(12):1843-1854.

[23] Shankar MG, Shivaprakash YM, Jayashree PK, Gurumurthy BM, Sharma S. Study on tensile strength on artificially aged Al-Mg-Si alloy using Taguchi's technique. International Journal of Mechanical Engineering and Technology. 2019;10(1):13121320.

[24] Rajasekaran S, Udayashankar NK, Nayak J. T4 and T6 treatment of 6061 Al-15 Vol.\% $\mathrm{SiC}_{\mathrm{p}}$ composite. International Scholarly Research Network,2012;1:1-5.

[25] Nieh TG, Karlak RF. Aging characteristics of $\mathrm{B}_{4} \mathrm{C}$-reinforced 6061-aluminium. Scripta Metallurgica. 1984;18(1):25-28.

[26] Shankar G, Sharma SS, Kini A, Praksh S. Influence of artificial aging on the stir cast Al6061-sic metal matrix composites under different aging conditions. International Journal of Technology. 2016;7(6):1000-1008.

[27] Park YS, Lee SB, Kim NJ. Microstructure and mechanical properties of strip cast AlMg-Si-X alloys. Materials transactions. 2003;44(12):2617-2624.

[28] Gracio JJ, Barlat F, Rauch EF, Jones PT, Neto VF, Lopes AB. Artificial aging and shear deformation behaviour of 6022 aluminium alloy. International Journal of Plasticity. 2004;20(3):427-445.

[29] Prakash YS, Shankar MC, Sharma SS, Kini A. Property enhancement during artificial aging of Al6061-Silicon Oxide metal matrix composites. Materials Today: Proceedings. 2018;5(11):24186-24193.

[30] Miao WF, Laughlin DE. Precipitation hardening in Aluminium alloy 6022. Scripta Materialia. 1999;40(7):873-878.

[31] Toptan F, Kilicarslan A, Karaaslan A, Cigdem M, Kerti I. Processing and microstructural characterisation of AA1070 and AA6063 matrix $\mathrm{B}_{4} \mathrm{C}$ reinforced composites. Materials \& Design. 2010;31:S87-91. 